\title{
The Development of Control Systems Electromagnetic Lifting Installation
}

\author{
Altyn A. Aikeyeva, Bakhyt A. Zhautikov, Kanat M. Makhanov, Aigerim. R. Tanskozhanova, Perizat A. \\ Mukhtarova, and Arailym E. Ayubekova
}

\begin{abstract}
This work is directed to the development of the management system of electromagnetic lifting installation. To develop such control system it is necessary to create automatic system of switching the poles. The experiment model of levitation system is developed for carrying out prior experiments. The Arduino UNO platform on the basis of the Atmega328 microcontroller is chosen. In the work the description of $\mathrm{L293D}$ driver is presented and the principle of driver operation which is a part of the circuit is considered.
\end{abstract}

Index Terms-Electromagnetic lifting installation, microcontroller, Arduino Uno, L293D circuit driver, pulse width modulation.

\section{INTRODUCTION}

This article is written on the basis of results of the researches which are carried out within grant financing of the Ministry of Education and Science of the RK on the subpriority of "Technology of minerals", on the theme "Justification and Development of Energy Saving Technology of Rocky Mass Dredging by Means of Creation of Electromagnetic Lifting Installation", and also on the priority "Power and Mechanical Engineering" on the theme "Development of the System of Automatic Control and Complex Protection of Energy Saving Electromagnetic Lifting Installation".

Now there are not enough generalized theoretical and experimental studies which could be used while calculation and projection of the electromagnetic lifting installation based on magnetic levitation.

The substance of the offered technology is concluded in application for rise and motion of skip of electromagnetic field force (a magnetic levitation) for realizing ropeless rise [1].

\section{Statement of the Problem}

Ensuring skip motion in the horizontal as well as vertical direction requires the ordered switching of poles of electromagnets in the directing devices. Ensuring

Manuscript received June 23, 2016; revised January 22, 2017. This work was supported in part by the U.S. Department of Commerce under Grant BS123456.

A. A. Aikeyeva, K. M. Makhanov, A. R. Tanskozhanova, and A. E. Ayubekova are with the Karaganda State University named after the academician E. A. Buketov, Kazakhstan (e-mail: aikeeva@ mail.ru, makanov@inbox.ru, aika_3093@mail.ru, araika1995@mail.ru).

A. B. Zhautikov is with the Atyrau State University named after Kh. Dosmukhamedov, Kazakhstan (e-mail: bakhyt_zhautikov@mail.ru).

P. A. Mukhtarova is with the Asian Pacific University of Innovations and Technologies, Malaysia (e-mail: mukhtarova_p@mail.ru). trouble-free operation of electromagnetic lifting installation requires switching polarities of hundreds of electromagnets. It causes the necessity of automatic control system development.

During the motion skip is under the influence of forces various in their origin and character. The specified forces can be subdivided into electrodynamic and mechanical.

The results of the experimental and theoretical studies for a range motion speeds inherent in installations with a magnetic suspender showed that the force of aerodynamic resistance of the air environment is the dominating making resultant force of the skip motion resistance.

Forces operating on the skip from the air environment at the most common problem setting are defined by the main vector of aerodynamic force and its main moment concerning the center of masses.

The experiment model of levitation system is developed for carrying out prior experiments [2].

\section{The MEthod of CAlCulation}

The developed experimental model consists of one directing device and the cart moving on it. The circuit of the experiment model corresponds to Fig. 1.
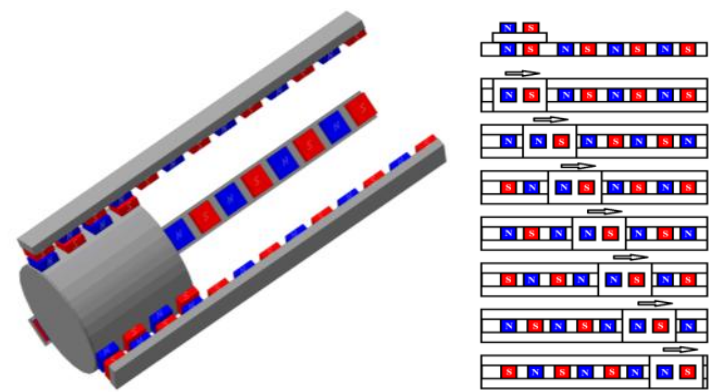

Fig. 1. The circuit of the experiment model.

The directing device consists of the directing conductor and electromagnets. The directing conductor electromagnets with alternation of the south and north poles are established on the whole length. In the directing conductor there are grooves for hinges. On the cart two electromagnets with alternation of poles and hinges are established.

Power supply voltage on electromagnets is given in the way that when unlike poles of electromagnets on the conductor and the cart are attracted, the similar poles of electromagnets make a start. Thanks to it the cart is set in motion. The motion speed of the cart is regulated by the electromagnetic force of electromagnets depending on power voltage [3]. The ratio of mass of electromagnet and its drag force matters. 
During the research several experimental stands of levitation system were developed.

Experiments were carried out with use of three types of electromagnets: with the ferrite core, steel core and electromagnet of the zye1-P25/20 model.

Characteristics of cores of electromagnets re specified according to Tables I-III.

TABLE I: KEY PARAMETERS OF THE FERRITE CORE

\begin{tabular}{|c|c|c|c|c|}
\hline \multirow{2}{*}{$\begin{array}{l}\text { Geometrical sizes } \\
\text { and } \\
\text { electromagnetic } \\
\text { parameters }\end{array}$} & \multicolumn{4}{|c|}{ Brands of ferrite, standard sizes } \\
\hline & $\begin{array}{l}\mathrm{M} 600 \mathrm{HH}, \\
\mathrm{C} 3.5 \times 20\end{array}$ & $\begin{array}{l}\mathrm{M} 600 \mathrm{H} \\
\mathrm{H}, \\
\mathrm{C} 4 \times 45\end{array}$ & $\begin{array}{l}\text { M400HH } \\
\text {, C. } 8 \times 63\end{array}$ & $\begin{array}{l}\mathrm{M} 2000 \mathrm{H} \\
\mathrm{M}, \\
\mathrm{C} 6 \times 25\end{array}$ \\
\hline 1 & 3,5 & 4,0 & 8,0 & 6,0 \\
\hline Diameter is $\mathrm{D}, \mathrm{mm}$ & 3,5 & 4,0 & $4^{8,0-0,}$ & 6,0 \\
\hline $\begin{array}{l}\text { Length of core } \mathrm{L} \text {, } \\
\mathrm{mm}\end{array}$ & 20 & 45 & 63 & 25 \\
\hline $\begin{array}{l}\text { Mass } \mathrm{m}, \mathrm{g} \quad \text { (no } \\
\text { more) }\end{array}$ & 4 & 7 & 17 & 10 \\
\hline $\begin{array}{l}\text { Inductance of the } \\
\text { measuring coil with } \\
\text { the core Lcc }(\mathrm{mcH})\end{array}$ & 500 & 500 & 300 & 1500 \\
\hline
\end{tabular}

\begin{tabular}{|l||l||l||l||l|}
\hline $\begin{array}{l}\text { Initial magnetic } \\
\text { conductivity } \mu \mathrm{H}\end{array}$ & 600 & 600 & 400 & 2000 \\
\hline
\end{tabular}

TABLE II: Key PARAMETERS OF THE STEEl CoRE (BolT)

\begin{tabular}{|l||c||c||c||c||}
\hline \multirow{2}{*}{$\begin{array}{l}\text { Geometrical sizes and } \\
\text { electromagnetic } \\
\text { parameters }\end{array}$} & \multicolumn{3}{|c||}{ Brands of steel, standard sizes } \\
\cline { 2 - 5 } & $\mathrm{M} 6$ & $\mathrm{M} 8$ & $\mathrm{M} 10$ & $\mathrm{M} 12$ \\
\hline \hline Diameter is D, mm & 6 & 8 & 10 & 12 \\
\hline \hline Length of core L, mm & 16 & 18 & 20 & 25 \\
\hline \hline Mass m, g (no more) & 5,93 & 12,53 & 24,97 & 39,95 \\
\hline $\begin{array}{l}\text { Inductance of the } \\
\text { measuring coil with } \\
\text { the core Lcc (mcH) }\end{array}$ & 500 & 700 & 900 & 1100 \\
\hline $\begin{array}{l}\text { Initial magnetic } \\
\text { conductivity } \mu \mathrm{H}\end{array}$ & 600 & 800 & 1000 & 1200 \\
\hline
\end{tabular}

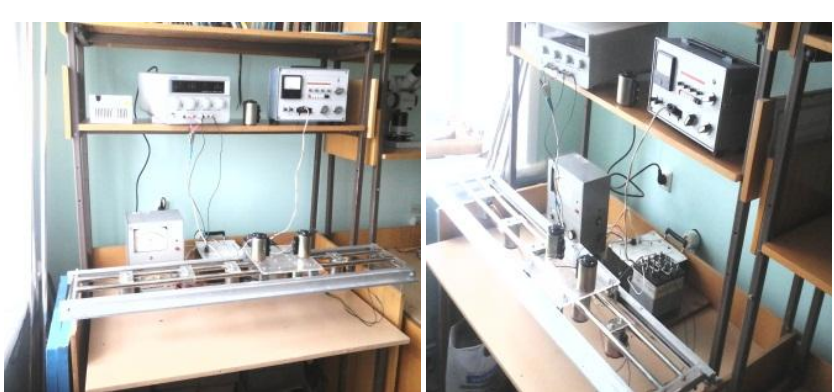

Fig. 2. Experimental model of levitation system.

TABLE III: Key PARAMETERS OF ElECTROMAGNET OF THE ZYE1-P25/20 MODEL

\begin{tabular}{|c|c|c|c|c|c|c|c|}
\hline Brand & Power consumption & Input voltage & Current & Weight & Load-carrying capacity & Deduction force & Diameter \\
\hline zye1-P25/20 & $4 \mathrm{WW}$ & $12 \mathrm{~B} \mathrm{DC}$ & $0.33 \mathrm{~A}$ & 49 г & $5 \mathrm{~kg}$ & 50N/11LBS & $5.75 \mathrm{~cm} / 1.48$ inches \\
\hline
\end{tabular}

Also in researches neodymium magnets characteristics were used which are specified in Table IV.

TABLE IV: KEY PARAMETERS OF NEODYMIUM MAGNETS

\begin{tabular}{|l||l||}
\hline Size: & $10^{*} 40 \mathrm{~mm}$ \\
\hline \hline Weight: & $24.01 \mathrm{~g}$ \\
\hline \hline Type: & $\mathrm{N} 35$ \\
\hline \hline Material: & $\begin{array}{l}\text { Nd-Fe-B (neodymium } \\
\text { magnet) }\end{array}$ \\
\hline \hline Magnetization: & axial \\
\hline \hline Separation force: & $3.79 \mathrm{~kg}$ \\
\hline
\end{tabular}

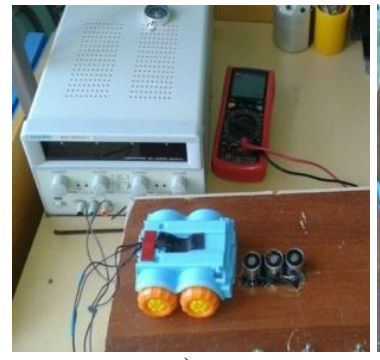

a)

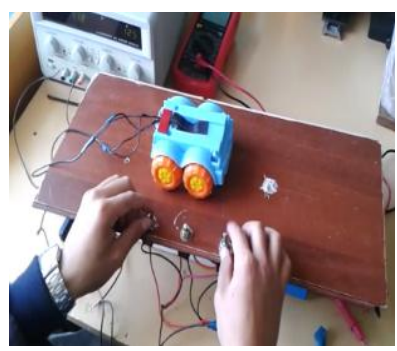

c)

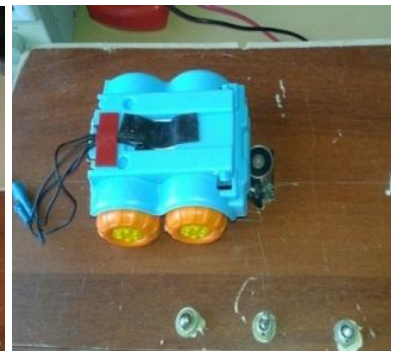

b)

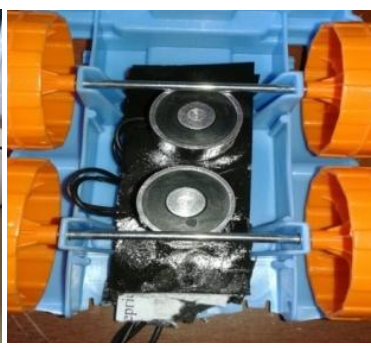

d) a) the cart motion in initial position, b) the cart in the middle, c) at the end g) electromagnets located under the cart

Fig. 3. The cart motion in the horizontal direction.
A number of experiments was carried out as a result of which model motion of the skip (cart) in horizontal the direction was gained according to Fig. 3.

On the lower platform of the stand electromagnets with the alternating polarity are installed. Also, at the bottom of the skip (cart) model two electromagnets with the alternating polarity are located. Electromagnets on the cart and on the platform are located in the way that when switching polarity of electromagnets on the platform the cart is set in motion. Also the experiments with electromagnets of other types were made: with ferrite cores and steel cores [4].

The experiment showed that traveling speed of skip model with application of electromagnets with steel cores is more than with application of electromagnets with ferrite cores.

Though drag force of the ferrite core is higher, but the experimental experience showed that when using steel cores traveling speed of the experimental model (cart) is more. It is possible to explain it with the fact that force of interaction of electromagnets with the steel core is more than electromagnets with the ferrite core.

Further, the experimental stand of vertical movement is assembled

At this stand three directing devices located under 120 degrees relatively each other are installed. During the research some experimental stands of levitation system, consisting of one directing device and the cart moving on it and three directing devices located at 120 degrees relatively each other were developed. Inside on the skip the neodymium magnets located also at 120 degrees relatively each other with the alternating polarity are established. The directing device consists of the directing conductor and electromagnets. On all length of the directing conductor electromagnets with 
alternation of the south and north poles are established. The choice of parameters of electromagnets is carried out [5].

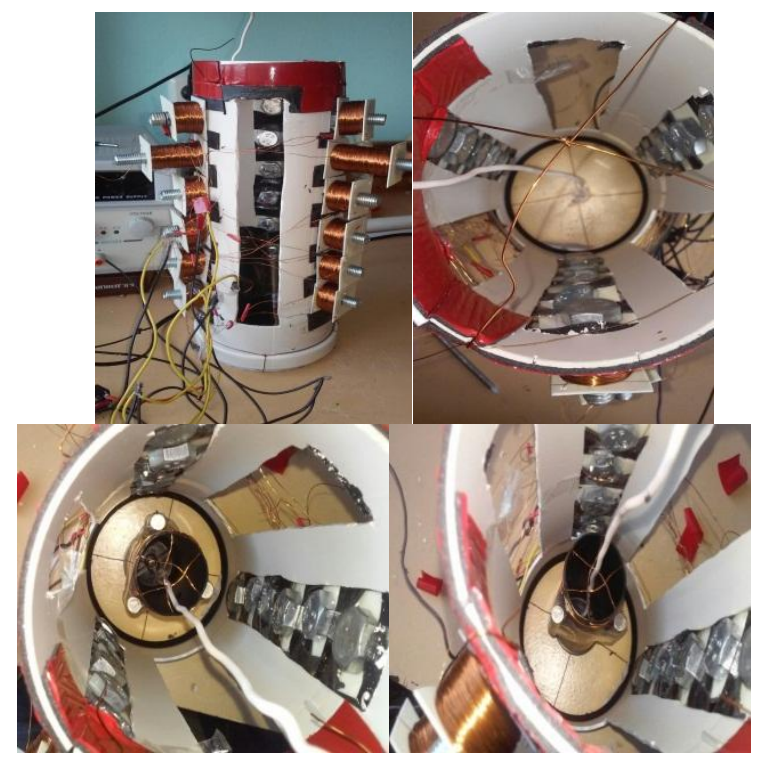

Fig. 4. The experimental model of the skip.

In the course of the research it was necessary to calculate key parameters of electromagnet. The main problem was to define drag force of electromagnets with the ferrite core and the steel core.

It was necessary to use characteristics of cores and copper wire in order to determine key parameters of electromagnets. While passing of electric current through the coil placed in its steel (ferrite) core gains properties of natural magnet.

The extent of magnetization of the steel (ferrite) core determined by the size of the magnetic flux passing through that is judged by the maximal mass of the attracted freight (load-lifting force of electromagnet) depends on the current intensity passed through the coil, numbers of winds and temperature of the coil, chemical composition, form, size and temperature of the lifted load.

During the research it became obvious that the coil without steel (ferrite) core will also have magnetic properties - to attract magnetizing bodies, but the attractive force at the same current passing through it is much less, than at the coil with the steel (ferrite) core. This is explained from the fact that magnetic conductivity of air is much less, than the steel (ferrite) core.

The magnetic flux of electromagnet is defined by magnetizing force $\mathrm{F}$, amperwind:

$$
F=I \omega
$$

where $I$ - the current passing through its coil, $A ; \omega-$ number of winds of the coil, and also magnetic conductivity of the chain consisting of the core of electromagnet and the lifted load.

Magnetic conductivity is not a stationary value and depends on the size of magnetizing force. With body height of magnetizing force magnetic conductivity at first increases sharply, reaches the maximal size then there occurs saturation; increase gives slight increase in magnetic flux until when increase in magnetizing force is practically not followed by further increase in magnetic flux.
Approximate calculation of load-lifting force of electromagnet can be performed by the following formula:

$$
P=\frac{40,6 \Phi^{2}}{S} 10^{4}
$$

where $S$ - the area of interaction between magnet poles of the platform and the skip, $\mathrm{mm}^{2} ; \Phi-$ magnetic flux, $\mathrm{Wb}$, equal

$$
\Phi=\frac{F}{R_{\mu}}
$$

$R \mu$ - electromagnet circuit resistance.

$$
R_{\mu}=\frac{l}{\mu \mu_{0} S}
$$

where $l$ and $S$ - length and transverse section of the site of the magnetic circuit, $\mu-$ the relative magnetic conductivity of circuit material, $\mu 0$ - magnetic constant.

To find the current passing through its coil the Ohm law is applied:

$$
I=\frac{U}{R}
$$

where $U=12 \mathrm{~B}$, R-resistance which is determined by the formula:

$$
R=\rho \frac{l}{S}
$$

where $R$ - resistance, Ohm; $\rho$ - specific resistance, $(\mathrm{Ohm}$ $\mathrm{mm}^{2}$ ) / $\mathrm{m} ; 1$ - length of wire, $\mathrm{m} ; \mathrm{S}$ - sectional area of wire, $\mathrm{mm}^{2}$.

If the diameter of the wire is known, then the area of its section is equal:

$$
S=\frac{\pi d^{2}}{4}
$$

Length of the wire is equal:

$$
l=d \pi \omega
$$

where $d$ - average diameter of winding, $\omega$ - number of coil winds.

$$
L=\mu \mu_{0} \frac{\omega^{2} S}{l}
$$

where $\omega$ - number of winds, $S$ - sectional area, $l$ - coil length, $\mu$-relative magnetic conductivity of the environment filling the coil, $\mu 0=4 \pi \cdot 10-7 \mathrm{H} / \mathrm{m}-$ magnetic constant.

We will define a sectional area of the solenoid as the area of a circle:

$$
S=\frac{\pi D^{2}}{4}
$$

Let's substitute this in the inductance formula, and we will express number of winds: 


$$
\begin{gathered}
L=\mu \mu_{0} \frac{\omega^{2} \pi D^{2}}{4 l} \\
\omega=\sqrt{\frac{4 L l}{\mu \mu_{0} \pi D^{2}}}
\end{gathered}
$$

The results of calculation showed that drag force of electromagnets with the ferrite core appeared more, than with the steel core. Ferrite possess the least losses for vortex currents and respectively can work at the highest frequencies from all magnetic materials. However, they have small induction of saturation. Their distinctiveness is the strong dependence of parameters on temperature, and also a material aging, deterioration in its properties over time. The range of application of each brand of ferrite is defined by the critical frequency, above which sharply increases losses and magnetic conductivity decreases. In cores in the form of steel ones vortex currents play positive role. At the same inductance the core even increases the coil quality.

For the solution of the problem of automatic switching of polarity of the used electromagnets the circuit consisting of the relay, transistor key of the pulling together resistors was developed and constructed.

As the operating part the Arduino Uno platform on the basis of Atmega328 microcontroller was chosen. The choice is caused first of all by opportunities of this board, availability of buffer elements (for example L293D), simplicity and availability of the programming environment, etc.

Layout scheme has been developed that illustrates switching the polarity og the electromagnets guide device in accordance with Fig. 5.

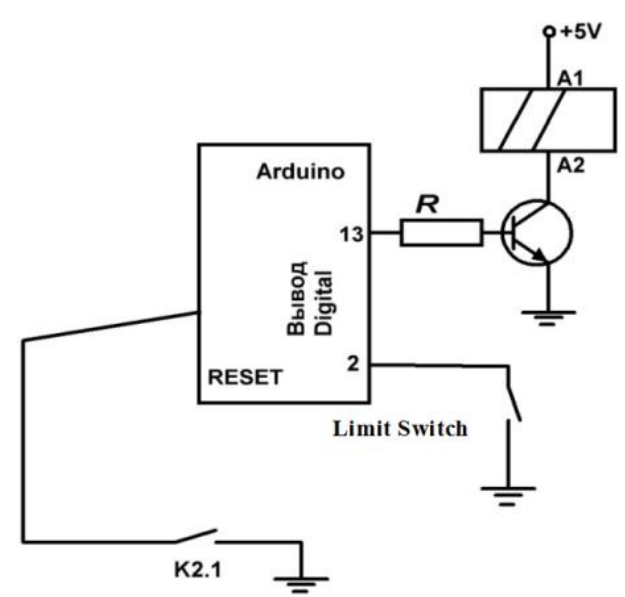

Fig. 5. Prior switching circuit of electromagnets polarities.

As performing element (switch) we used the one-channel module SRD-5VDC-SL-C relay as it allows to operate loading with high current or voltage easily.

This relay has the standard interface thanks to which it is possible to operate it immediately by means of the microcontroller, that was carried out by us. As the relay which was available to us was started from voltage 5 volts, and it was necessary to switch $12 \mathrm{~V}$, we were forced to use the KT805 series transistor as a key. The second reason of transistor use was that the inverse breakdown with the relay was possible that would lead to inevitable failure of the microcontroller. Transistor KT805 is bipolar transistor, structures - n-p-n. For protection of the controller an unclosing of base is carried out by means of resistor with resistance about $220 \mathrm{kOhm}$.

The developed scheme worked in the following sequence. The high level at the exit of the microcontroller, lasting 200 microsec opens base of the transistor. At the same time transition collector - emitter opens. The collector is connected to positive entrance of the relay. The switched contact of the relay connects the first (conditionally) electromagnetic coil in the corresponding polarity to this scheme. Then, 200 microsec later the high level at the exit of the microcontroller changes on low, at the same time the base of the transistor is closed that automatically closes emitter collector transition. Respectively the relay is switched-off, and the switched contact returns to the original state, i.e. change of connection polarity of the second (conditionally) coil is carried out.

As a result the scheme works as follows: one transistor operates polarity change in turn of two coils. In turn, for these coils the inverse change of polarity has to be carried out by means of other relay. That is, on both sides of the coil about one transistor is located and depending on time of switching on and switching off they in turn switch polarity of coils.

This circuit has both advantages and shortcomings. The advantages refer to nearly $100 \%$ of relay contacting. Possibility of switching considerably high currents, etc. However, as it was already noted there are also shortcomings. And first of all, it is "bulkiness" and considerably high cost of the circuit due to use of a large number of relay [6].

The attempt of use full-wave circuit consisting of four transistors was made. On each end of the coil we connected two transistors of various structure of $p-n-p$ and n-p-n. The idea was simple if to open two counter transistors with various base conduction at the same time, it is possible to change polarity of the coil by alternating the pairs of transistors. Duration and time of inclusion is defined programmatically.

As well as in the first case, this full-wave circuit has the advantages and shortcomings.

It was necessary to develop such a scheme in which the quantity of the used details would be minimum, and the operating ends of the microcontroller were enough for 10-12 electromagnetic coils.

Therefore it was expedient to include the circuit into the scheme which would allow to leave larger quantity of pins and to provide protection of voltage leaps and current at the time of switching electromagnets [7].

The review of literary data revealed the existence of chips, their scheme and logic of work allowed their use for realization of objective. One of such chips is L293D. The choice of the given series is caused by rather high parameters of the operating current. According to principal specifications of this series in peak situations, the commutation of currents to 1,6 amperes is possible. This value quite satisfied our requirements. Besides, one chip with its number of ends and the order of their connection allowed commutation of two coils at the same time. One of advantages of this series chip L293D is existence of the firmware diodes. Diodes are switched on in reverse polarity, that protects of the scheme. As the operating part we left Arduino board [8]. 
This version of the scheme for switching of coil polarity was the most valid from the position of choice the executive elements. Using only one chip we had an opportunity to operate polarity of a power supply of two coils.

Thus, the scheme of management similar to the scheme of management of the three-phase engine according to the Fig. 6 was taken as a basis of the scheme developed by us.

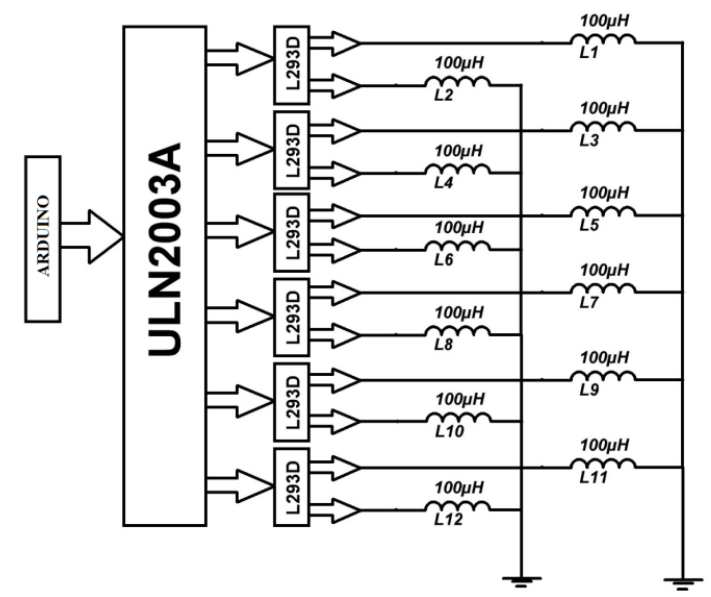

Fig. 6. The switching scheme with use of the key ULN2803A.

Imitation of electromagnetic coils polarity switching was made. It is necessary to operate time of switching on and offprecisely for achievement of maximum efficiency of operation according to Fig. 7.

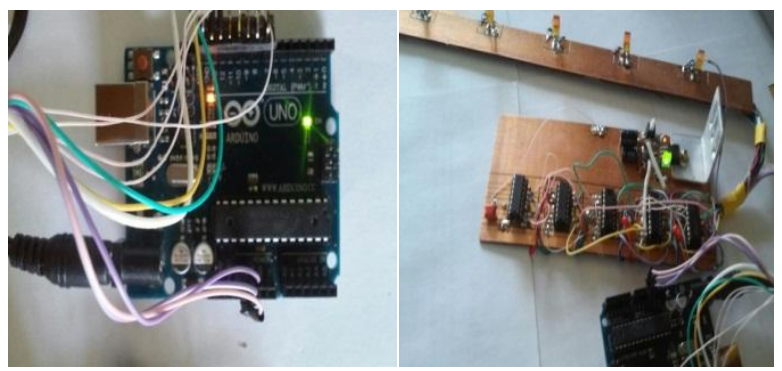

Fig. 7. Model of operating electromagnets polarity switching.

\section{CONCLUSION}

Thus, we developed the imitating models of the design of electromagnetic lifting installation which are in a complex considering design technology factors, and ensuring trouble-free operation of electromagnetic lifting installation. In operation the switching scheme wide - pulse signal modulation is used that is similar to the scheme of control of the three-phase engine

For ensuring trouble-free operation of electromagnetic lifting installation switching circuits of electromagnets polarity in the directing devices with optimum number of the used details are found and developed. Operation on the basis of the Arduino UNO platform with the Atmega328 microcontroller. The control circuit switching used pulse the pulse signal modulation scheme similar three-phase motor control. The scheme has the firmware protection against overheat and overloads.

\section{REFERENCES}

[1] B. A. Zhautikov, A. A. Aikeyeva, F. B. Zhautikov, and P. A. Mukhtarova, Electromagnetic Lifting Installation (Unit)//Innovative, patent № 27177, the ministry of Justice of Republic of Kazakhstan.
[2] V. A. Trudnoshin and N. V. Pivovarova, Mathematical Models of Design Objects, p. 134

[3] M. R. Nurguzhin, T. Y. Katsaga, and G. T. Danenova, Laboratory workshop on mathematical modeling of design objects at the macro and micro levels: A tutorial, Karaganda: KSTU, p. 104, 2001.

[4] B. J. Soviets, Simulation Systems, Moscow, p. 343, 2001.

[5] B. C. Pugachev, Sinitsyn IN Theory of Stochastic Systems, M.: Logos, 2000.

[6] Kudryavtsev EM GPSS World, "Basics of simulation of different systems," Scientific Publication, M.: DMK Press, p. 317, 2004.

[7] Intelligent Systems of Automatic Control, THEM. Makarov VM Lokhin, M.: FIZMATLIT, 2001.

[8] M. R. Nurguzhin, G. T. Danenova, and T. Y. Katsaga, "Mathematical modeling: Course design,” Textbook, Karaganda: KSTU, p. 101, 2001.

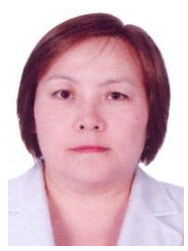

Aikeyeva Altyn Amanzholovna was born on February 21, 1967 in Karaganda, Kazakhstan. In 1991 she graduated from the Leningrad Electrotechnical Institute named of V. I. Ulyanov (Lenin), qualification "electrical engineer".

In 1995 she was accepted as an assistant of the Department "Electrical Engineering" Karaganda State Technical University. Since 1998, she was a senior lecturer at the Department "Power and Electrical Engineering". From 2006 to 2009, she was a deputy dean of the Faculty of Energy, Communications and Automation KSTU, from August 2009 to September 2010, she was the head of the Department "Technology and communication systems" KSTU. Since October 2010, she worked as the Head of Educational Department Rudny Industrial Institute. Since September 2012, she was an associate professor, and now professor of "Radio Physics and Electronics" Karaganda State University named after EA Buketov.

Aikeyeva A. A. in 2009 defended her thesis on the specialty 05.05.06 "Mining machines" with a hot topic for the industry of the country, "Research and selection of the parameters of the sealing devices mine skip pneumolift installations." She is the author of over 40 scientific publications. In 2011, "Electrical Engineering" by the Committee for Control of Education and Science of the MES RK awarded the title of associate professor. The owner the Innovation patent for invention "Electromagnetic lifting unit (options).

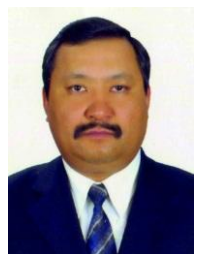

Zhautikov Bakhyt Akhatovich was born on August 27 1963.

In 2008, He is a Doctor of Technical Sciences, in 2009 - Professor. Works in Atyrau State University H Dosmukhamedov, First Vice-Rector. He has more than 90 scientific works, 4 copyright certificates for the invention of the USSR, 3 patents of RK. He is the author of 25 electronic textbooks, 10 manuals, more than 25 educational and methodological developments. He awarded the Certificate of Merit of the Minister of Education and Science (2006), the badge "Honorary Worker of Education of the Republic of Kazakhstan".

Zhautikov B. A. is corresponding Member of the National Engineering Academy of the Republic of Kazakhstan. He has the badge "Honorary Worker of Education of the Republic of Kazakhstan". He participated in the project Analysis of the application of electromagnetic lifting systems for excavation of the rock mass conditions in the mining industry in Kazakhstan The owner the Innovation patent for invention "Electromagnetic lifting unit (options).

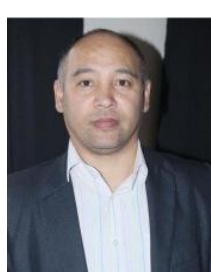

Makhanov Kanat Metovich was born on September 4, 1973 in Karkaraly, Karaganda region, Kazakhstan. In 1994, he entered the Faculty of Physics of the Karaganda State University named after E.A.Buketov in the speciality "Physics". In 1999 entered in graduate school of KSU.

In 2004 defended his thesis for the degree of candidate of physical - mathematical sciences, specialty "Condensed Matter Physics". In 2009 he was elected by competition assistant professor of spectroscopy of the condensed state.

Makhanov K. M. is working as assistant professor of the department "Radiophysics and electronics" Physical - Technical Faculty of the Karaganda State University named after E.A.Buketov. According to the results of research published over 30 scientific papers. Of these 4 articles published in scientific journals abroad, such as: «Molecular Crystals and Liguid Crystals». He is the author of a textbook.He is the head of the circle "Fundamentals of Robotics." As part of this circle under his supervision the 
work which marked prizes at national and international competitions and contests on robotics.

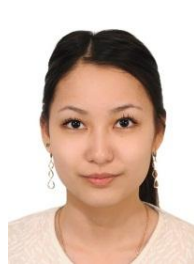

Tanskozhanova Aigerim Rakhmetollaevna was born on September 30, 1993 in Karaganda, Kazakhstan. 2000-2011 studied in gymnasium № 92. In 2015, she graduated from the Karaganda State University named after the academician E.A. Buketovin the speciality "Radiophysics, electronics and telecommunications".

In 2015, she received on master's degree on the speciality "Technical Physics"; and received a diploma in the nomination "The relevance of scientific problems" in the regional scientific-practical conference of students and undergraduates "Buketov Reading-2016" (head Aikeyeva AA).

Tanskozhanova A. A. is engineer in the Karaganda State University named after the academician E. A. Buketov.

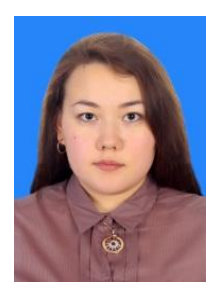

Mukhtarova Perizat Askhatovna was born on May 10, 1994 in Karaganda, Kazakhstan.

She is studying at Asia Pacific University of Technology and Innovation in Kuala Lumpur, Malaysia.

In May of 2014, World Intellectual Property Organization (WIPO) awarded her as a Best Young Inventor. In 2014, she was participating in the project about "Rationale and design of energy-saving technology for transporting rock mass by creation electromagnetic hoisting installation". In 2015 received the diploma of the first degree obtained at the X International Scientific Conference of students and young scientists "Science and Education - 2015". Diploma "For the best scientific work" and a gold medal for their participation in the contest "The Foundation of the First President of the Republic of Kazakhstan - Leader of the Nation". The owner the Innovation patent for invention "Electromagnetic lifting unit (options).

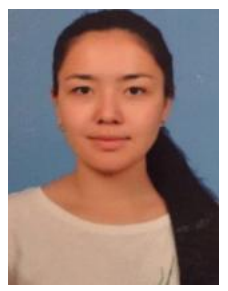

Ayubekova Arailym Erlanovna was born on April 27, 1995 in Satpayev, Karaganda region, Kazakhstan From 2002 to 2009, she studied in gymnasium №1. From 2009 to 2013, she studied in gymnasium named Saken Seifullin.

Since 2013, she was studying on 3 course of the Karaganda State University named after the academician E. A. Buketov in the speciality "Radiophysics, electronics and telecommunications". She received a diploma in the nomination "The relevance of scientific problems" in the regional scientific-practical conference of students and undergraduates "Buketov Reading-2016" (head Aikeyeva AA).

Since 2016, Ayubekova A. A. is working part-time positions as a laboratory assistant in the Karaganda State University named after the academician E. A. Buketov. 